\title{
Impact of atmospheric circulation patterns on coastal dune dynamics, NW Spain
}

\author{
R. González-Villanueva a,*, S. Costas ${ }^{a}$, M. Pérez-Arlucea ${ }^{\text {b }}$, S. Jerez ${ }^{\text {c }}$ R.M. Trigo ${ }^{\text {c,d }}$ \\ a Unidade de Geologia Marinha (UGM), LNEG, 7586, Lisbon, Portugal \\ ${ }^{\mathrm{b}}$ Dpto. Xeociencias Mariñas e O.T. (XM1), 36310, Universidade de Vigo, Spain \\ c Instituto Dom Luiz, Universidade de Lisboa, 1749-016 Lisboa, Portugal \\ d Departamento de Engenharias, Universidade Lusófona, 1749-024 Lisboa, Portugal
}

\section{A R T I C L E I N F O}

Article history:

Received 3 August 2012

Received in revised form 13 December 2012

Accepted 16 December 2012

Available online 24 December 2012

\section{Keywords:}

Aeolian activity

Blowout

Climate variability

Dune stabilization

SW Europe

\begin{abstract}
A B S T R A C T
Dunes in temperate latitudes have experienced a significant stabilization in recent times, essentially as a consequence of the expansion of dense vegetation cover. Yet, the causes for this gradual stabilization as well as the causes promoting antecedent aeolian mobilization remain poorly understood. The Traba coastal dune field, located in NW Spain, was examined to explore the causes inducing aeolian activity and subsequent stabilization since 1940. Morphological changes were identified through the combination of aerial photographs and geophysical techniques. Local wind field regimes were simulated using a regional climate model to obtain the variability of the most relevant modes of atmospheric circulation in the North Atlantic and European regions; North Atlantic Oscillation (NAO), Eastern Atlantic (EA) and Scandinavian (SCAND). This allows us to identify the impact of these circulation modes over dune dynamics. Results document an episode of aeolian activity during the 1950s followed by a gradual stabilization and fixation of the dune coincident with a decrease on storm and wind intensity. Yet, aeolian sand movement remained active in small areas (blowouts), occurring mainly during the summer. $\mathrm{NE}$ winds associated with a negative phase of the EA explain the movement of sand within the dune field under favorable conditions of sand supply. On the other hand, sand supply to the dune field from the beach was promoted by NW winds coincident with the summer negative phase of NAO. During winter, the negative NAO favored frequent SW winds associated with the passage of intense storms, which in turn explain sand remobilization from the beach making sediment available for the NW winds to blow inland. With this work, it is proven that to understand past and future aeolian activity requires critical consideration of the variability and impact of the two principal modes of atmospheric circulation in the North Atlantic (NAO and EA). The SCAND mode explaining a lower percentage of the local wind field variability was also included to achieve higher significance levels of explained variance.
\end{abstract}

(C) 2012 Elsevier B.V. All rights reserved.

\section{Introduction}

Aeolian dunes are the result of complex histories of alternating events of sand drift and dune stabilization. Natural dune stability and mobility are influenced by three major factors: climatic variables (i.e. wind, precipitation, moisture), sediment characteristics (i.e. availability, grain size) and vegetation cover (Klijn, 1990; Pye, 1993). Episodes of aeolian activity have been linked repeatedly to an increase of sediment supply (Davidson-Arnott and Law, 1996; Aagaard et al., 2004) and changes in climate conditions (Gaylord and Stetler, 1994; Tsoar et al., 2009). On the European coasts, enhanced storminess has often been invoked as a major causal factor for the initiation of dune activity (Clemmensen et al., 1996; Wilson and Braley, 1997; Wilson et al., 2001; Clarke et al., 2002; Clarke and Rendell, 2009; Costas et al., 2012). However, the actual mechanism responsible for the reactivation of aeolian activity in coastal systems remains poorly understood (Bailey

\footnotetext{
* Corresponding author.

E-mail address: rita.gonzalez@Ineg.pt (R. González-Villanueva).
}

and Bristow, 2004; Buynevich et al., 2007; Girardi and Davis, 2010). Currently, most European coastal dunes have undergone a progressive stabilization as vegetation cover expanded, but the causes behind such a landscape shift remain under debate (Bailey and Bristow, 2004; Costas and Alejo, 2007; Arens et al., 2008; Jackson and Cooper, 2011). Several factors have frequently been inferred as possible causes for the growth of vegetation in coastal dunes, including anthropogenic pressure (i.e. changes in land use, landscape fixation, introduction of non-native species); semi-natural factors (i.e. crashing rabbit populations, eutrophication) or climatic-derived changes (i.e. enhanced $\mathrm{CO}_{2}$ concentration and temperature, diminished wind and storminess); see Provoost et al. (2011) for a review.

From a climate variability perspective, increased emphasis has been put on the role played by the most important large-scale mode of atmospheric circulation in the North Atlantic. The climate of Galicia, located in the northwestern corner of the Iberian Peninsula has been reviewed in detail in a recent special issue (Gimeno et al., 2011). It has been noticed that a relatively small number of these modes are responsible for a large fraction of the wind and precipitation 